\title{
Meningkatkan Kemampuan Argumentasi Ilmiah Siswa SMP Kelas VII melalui Bahan Ajar IPA Terpadu dengan Tema HALO pada Topik Kalor
}

\author{
Diterima 28 Maret 2018, Disetujui 2 April 2018, Dipublikasikan April 2018
}

\author{
RE Putri ${ }^{1, a)}$ \\ ${ }^{1}$ Departemen Pendidikan IPA, Universitas Negeri Padang, Jl. Prof. Dr, Hamka, Air \\ Tawar, Padang, Indonesia \\ a)E-mail: rahmahep@fmipa.unp.ac.id
}

\begin{abstract}
Abstrak. Penelitian ini merupakan penelitian semu (quasi experiment), dengan tujuan yakni meningkatkan kemampuan argumentasi ilmiah melalui bahan ajar IPA terpadu dengan tema Halo pada topik kalor. Bahan ajar yang digunakan yakni menggunakan bahan ajar ipa, yang dipadukan dengan model webbed, dan telah diuji kelayakannya menggunakan uji kelayakan berdasarkan kriteria BNSP. Kemampuan argumentasi ilmiah siswa diuji dengan menggunakan soal essai dengan cakupan materi perubahan wujud zat dan kalor. Hasil yang diperoleh nilai rata-rata pretest kelas kontrol lebih tinggi jika dibandingkan dengan kelas eksperimen pada saat pretest. Pada kelas kontrol didapatkan rata-rata sebesar 63,71 sedangkan dikelas eksperimen diperoleh nilai rata-rata sebesar 62,71. Sehingga kelas kontrol dan kelas eksperimen memiliki selisih nilai sebesar 1,00. Peningkatan argumentasi ilmiah antara kelas kontrol dan kelas eksperimen berbeda secara signifikan. Dimana kelas eksperimen yang belajar dengan menggunakan bahan ajar IPA terpadu dengan tema Halo mendapatkan nilai N-Gain pada kategori tinggi $(0,84)$ berbeda dengan kelas kontrol yakni kelas yang menggunakan bahan ajar IPA terpadu konvensional mendapatkan nilai N-Gain pada kategori sedang $(0,64)$
\end{abstract}

Kata kunci: Argumentasi Ilmiah, Bahan Ajar, IPA Terpadu

\section{Pendahuluan}

Ilmu Pengetahuan Alam (IPA) berkaitan dengan cara mencari tahu tentang alam secara sistematis, IPA tidak hanya penguasaan kumpulan pengetahuan yang berupa fakta-fakta, konsep-konsep, atau prinsipprinsip saja tetapi juga merupakan suatu proses penemuan. Pendidikan IPA diharapkan dapat menjadi wahana bagi peserta didik untuk mempelajari diri sendiri dan alam sekitar, serta prospek pengembangan lebih lanjut dalam menerapkan di dalam kehidupan sehari-hari. Pembelajaran IPA diharapkan dapat menumbuhkan kemampuan berpikir, bekerja dan bersikap ilmiah serta mengkomunikasikannya sebagai aspek penting kecakapan hidup (Depdiknas, 2006).

Menurut Forgaty (1991) menyatakan bahwa pembelajaran terpadu akan memberikan pengalaman yang bermakna bagi peserta didik, karena dalam pembelajaran terpadu peserta didik akan memahami konsep-konsep yang dipelajari melalui pengalaman langsung dan menghubungkannya dengan konsepkonsep lain yang sudah dipahami sesuai dengan kebutuhan peserta didik. Dalam proses pembelajaranpun IPA diharapkan disampaikan secara terpadu antara konsep-konsep fisika, kimia, biologi dan antariksa yang saling berkaitan, agar siswa dapat mengenal dan memahami IPA sebagai ilmu yang utuh.

Keterpaduan dalam IPA dapat dikembangkan dengan acuan keterpaduan konsep, sikap, atau keterampilan. Dengan berfokus pada salah satu atau lebih keterpaduan tersebut, maka pembelajaran terpadu akan memiliki tujuan yang jelas. Paradigma pembelajaran di abad 21 juga sudah berubah, terdapat beberapa ciri perubahan model pembelajaran yang menyesuaikan perkembangan zaman, diantaranya adalah informasi, komputasi, otomasi dan komunikasi. Kemendikbud (2012) menyatakan bahwa pekerjaan-pekerjaan di abad 21 memerlukan adanya komunikasi yang kompleks serta adanya kolaborasi dan kerjasama dalam menyelesaikan masalah. Komunikasi dan kolaborasi juga tak sekedar 
bekerja dalam kelompok yang kecil dan lokal tapi bisa jadi dalam skala yang besar dan global. Pembelajaran hendaknya diarahkan kepada melatih kemampuan berkomunikasi dan berkolaborasi dengan baik, Keterampilan yang dapat dilatih agar siswa-siswa menjadi manusia yang dapat berkontribusi bagi masyarakat dimana mereka dapat menerapkan hasil belajar yang dipelajari di sekolah ke dalam kehidupan bermasyarakat dan memiliki kemampuan berkomunikasi adalah keterampilan untuk berargumentasi secara ilmiah. Osborne (2004) argumentasi ilmiah memegang peranan penting dalam pembangunan, evaluasi, dan validasi dari pengetahuan ilmiah dan argumentasi merupakan praktek penting dalam sains yang dapat membedakan sains sebagai cara untuk mengetahui.

Kegiatan argumentasi merupakan proses dalam membentuk argumen, dimana tujuan dari argumentasi dalam sains bukanlah debat antar dua kelompok atau lebih yang menghasilkan pemenang atau usaha kompromi untuk memperoleh hasil yang saling menguntungkan, melainkan sebuah pernyataan logis yang tujuannya untuk mengeluarkan hubungan antara ide dan bukti (Duscl, Schweingruber, \& Shouse, 2007, dalam Sampson, 2010). Tujuan argumentasi dalam sains adalah memperoleh ide atau gagasan terbaik yang menghubungkan antara claim dan bukti dengan jelas. Pada proses argumentasi, siswa diminta untuk menjelaskan hubungan antara ide dan bukti, hal ini merupakan sarana utama agar siswa dapat memvalidasi ide sendiri dan mengembangkan kemampuan berpikir agar dapat menghubungkan ide dan bukti yang mereka temukan (Berland dan Hammer, 2012).

Dalam mengemukakan argumentasi, tentunya siswa harus mengetahui mengenai konsep pembelajaran tersebut terlebih dahulu. Ketika mengungapkan pendapat, tentunya pendapat atau argumentasi tersebut haruslah didasari dari teori dan konsep yang sesuai. Oleh karena itu, dalam mengungkapkan argumentasi secara ilmiah, siswa haruslah mengetahui konsep ataupun materi yang sesuai dengan pendapatnya, dan untuk menghubungkan antara ide dan bukti yang diungkapkan, siswa haruslah memahami terlebih dahulu konsep dan materi dari permasalahan tersebut. Agar nantinya argumentasi yang dikemukakan oleh siswa menjadi argumentasi yang bersifat ilmiah, maka argumentasi tersebut haruslah berlandaskan teori-teori yang bersifat ilmiah sebagai pembenaran dan dukungan. Sehingga, melatih kemampuan argumentasi ilmiah siswa haruslah sejalan dengan peningkatan penguasaan konsep, agar dalam mengungkapkan argumentasi, siswa memiliki dukungan dan landasan berupa teori yang kuat dan sesuai.

\section{Metode Penelitian}

Metode penelitian dalam penelitian ini adalah quasi eksperimen, karena subjek tidak dipilih secara random (Frenkel, Wallen dan Hyun, 2012). Desain penelitian yang digunakan dalam penelitian ini adalah Pretest-Postest Nonequivalent Control Group Design. Pada desain penelitian ini kemampuan kedua kelompok diukur dengan pretest sebelum perlakuan dan posttest setelah perlakuan. Pengukuran dilakukan pada waktu bersamaan pada kedua kelompok tersebut.

$\begin{array}{lccc}\begin{array}{l}\text { Tabel 1.1. Desain Penelitian Pretest-Postest Nonequevalent Control Group Design } \\ \text { Kelompok perlakuan }\end{array} & \mathrm{O} & \mathrm{X} & \mathrm{O} \\ & \mathrm{O} & \mathrm{C} & \mathrm{O} \\ \text { Kelompok kontrol } & & \end{array}$

Keterangan :

$\mathrm{O} \quad$ : Tes kemampuan argumentasi ilmiah

$\mathrm{X} \quad$ : Pembelajaran menggunakan bahan ajar IPA Terpadu dengan tema Halo

C : Pembelajaran menggunakan bahan ajar yang telah disediakan oleh pemerintah

Populasi dan sampel pada penelitian ini adalah seluruh siswa kelas VII SMP Negeri 1 Padang semester genap tahun ajaran 2015/2016 yang berjumlah 7 kelas. Sampel dari penelitian ini adalah dua 
Sekretariat: Jurusan Pendidikan IPA, Fakultas Matematika dan Ilmu Pengetahuan Alam, Universitas Negeri Padang - Jl. Prof. Dr. Hamka, Air Tawar Padang, Sumatera Barat

E-mail :prodiipa16@gmail.com, Halaman website : http://www.semesta.ppj.unp.ac.id/index.php/semesta.

Jurnal SEMESTA, Vol.01, No.01, 2017 pp. 34-46

kelas dari populasi yang ada. Teknik pengambilan sampel yakni dengan purposive sampling. Berdasarkan hasil observasi, didapatkan bahwa kedua kelas memiliki karakteristik yang homogen, dimana nilai rata-rata dari ulangan harian pada bab sebelumnya memiliki nilai yang hampir sama, sesuai dengan keaktifan siswa di dalam kelas yang juga hampir sama.

Tes kemampuan argumentasi ilmiah yang digunakan pada penelitian ini adalah soal kuosioner sehingga peserta didik dapat menuliskan argumen yang dimilikinya beserta informasi dan data yang mendukung argumennya tersebut.

Uji coba soal penguasaan konsep dan argumentasi ilmiah dilakukan pada siswa kelas IX SMPN Padang, Sumatera Barat. Soal yang diujicobakan berupa soal penguasaan konsep berbentuk pilihan ganda sebanyak 30 soal dan soal argumentasi ilmiah sebanyak 28 soal. Uji coba dilakukan untuk mengetahui validitas, reliabilitas, tingkat kesukaran dan daya pembeda soal. Analisis hasil uji coba soal menggunakan software Anatest V4 . Data hasil uji coba soal argumentasi ilmiah dapat dilihat pada Tabel 2.

Tabel 2. Hasil Uji Coba Soal Argumentasi Ilmiah

\begin{tabular}{|c|c|c|c|c|c|c|c|c|c|c|}
\hline \multirow{2}{*}{$\begin{array}{l}\text { No. } \\
\text { Soal }\end{array}$} & \multicolumn{2}{|c|}{ Validitas } & \multicolumn{2}{|c|}{ Reliabilitas } & \multicolumn{2}{|c|}{$\begin{array}{c}\text { Indeks } \\
\text { Kesukaran }\end{array}$} & \multicolumn{2}{|c|}{ Daya Pembeda } & \multirow{2}{*}{ Ket } & \multirow{2}{*}{$\begin{array}{c}\text { No } \\
\text { Soal } \\
\text { Baru }\end{array}$} \\
\hline & $\mathbf{r}_{\mathbf{x y}}$ & kategori & $\mathbf{r}_{11}$ & kategori & $\mathbf{P}$ & Kategori & D & Kategori & & \\
\hline 1 & 0,31 & rendah & & & 0,69 & sedang & 0,30 & diterima & dipakai & 1 \\
\hline 2 & 0,25 & rendah & & & 0,57 & sedang & 0,11 & direvisi & dipakai & 2 \\
\hline 3 & 0,35 & rendah & & & 0,63 & sedang & 0,44 & diterima & dipakai & 3 \\
\hline 4 & 0,28 & rendah & & & 0,43 & sedang & 0,11 & direvisi & dipakai & 4 \\
\hline 5 & 0,23 & rendah & & & 0,78 & mudah & 0,22 & direvisi & dipakai & 5 \\
\hline 6 & 0,33 & rendah & & & 0,61 & sedang & 0,33 & diterima & dipakai & 6 \\
\hline 7 & 0,38 & rendah & & & 0,57 & sedang & 0,56 & diterima & dipakai & 7 \\
\hline 8 & 0,33 & rendah & & & 0,37 & sedang & 0,22 & direvisi & dipakai & 8 \\
\hline 9 & 0,30 & rendah & & reliabel & 0,74 & mudah & 0,19 & direvisi & dipakai & 9 \\
\hline 10 & 0,42 & cukup & 0,73 & (tinggi) & 0,53 & sedang & 0,56 & diterima & dipakai & 10 \\
\hline 11 & 0,54 & cukup & & & 0,50 & sedang & 0,78 & diterima & dipakai & 11 \\
\hline 12 & 0,41 & cukup & & & 0,44 & sedang & 0,22 & direvisi & dipakai & 12 \\
\hline 13 & 0,31 & rendah & & & 0,69 & sedang & 0,19 & direvisi & dipakai & 13 \\
\hline 14 & 0,55 & cukup & & & 0,54 & sedang & 0,56 & diterima & dipakai & 14 \\
\hline 15 & 0,45 & cukup & & & 0,46 & sedang & 0,56 & diterima & dipakai & 15 \\
\hline 16 & 0,35 & rendah & & & 0,43 & sedang & 0,33 & diterima & dipakai & 16 \\
\hline 17 & 0,68 & tinggi & & & 0,61 & sedang & 1,22 & diterima & dipakai & 17 \\
\hline 18 & 0,67 & tinggi & & & 0,43 & sedang & 1,00 & diterima & dipakai & 18 \\
\hline
\end{tabular}


Sekretariat: Jurusan Pendidikan IPA, Fakultas Matematika dan Ilmu Pengetahuan Alam, Universitas Negeri Padang - Jl. Prof. Dr. Hamka, Air Tawar Padang, Sumatera Barat

E-mail :prodiipa16@gmail.com, Halaman website : http://www.semesta.ppj.unp.ac.id/index.php/semesta.

Jurnal SEMESTA, Vol.01, No.01, 2017 pp. 34-46

\begin{tabular}{|c|c|c|c|c|c|c|c|c|c|c|}
\hline \multirow{2}{*}{$\begin{array}{l}\text { No. } \\
\text { Soal }\end{array}$} & \multicolumn{2}{|c|}{ Validitas } & \multicolumn{2}{|c|}{ Reliabilitas } & \multicolumn{2}{|c|}{$\begin{array}{c}\text { Indeks } \\
\text { Kesukaran }\end{array}$} & \multicolumn{2}{|c|}{ Daya Pembeda } & \multirow{2}{*}{ Ket } & \multirow{2}{*}{$\begin{array}{c}\text { No } \\
\text { Soal } \\
\text { Baru }\end{array}$} \\
\hline & $\mathbf{r}_{\mathrm{xy}}$ & kategori & $\mathbf{r}_{11}$ & kategori & $\mathbf{P}$ & Kategori & D & Kategori & & \\
\hline 19 & 0,35 & rendah & & & 0,48 & sedang & 0,44 & diterima & dipakai & 19 \\
\hline 20 & 0,25 & rendah & & & 0,44 & sedang & 0,44 & diterima & dipakai & 20 \\
\hline 21 & 0,53 & cukup & & & 0,65 & sedang & 0,78 & diterima & dipakai & 21 \\
\hline 22 & 0,33 & rendah & & & 0,54 & sedang & 0,26 & direvisi & dipakai & 22 \\
\hline 23 & 0,03 & $\begin{array}{l}\text { sangat } \\
\text { rendah }\end{array}$ & & & 0,52 & sedang & 0,22 & direvisi & dipakai & 23 \\
\hline 24 & 0,19 & $\begin{array}{l}\text { sangat } \\
\text { rendah }\end{array}$ & & & 0,19 & sukar & 0,44 & diterima & dipakai & 24 \\
\hline 25 & 0,13 & $\begin{array}{l}\text { tidak } \\
\text { valid }\end{array}$ & & & 0,04 & sukar & 0,00 & ditolak & dibuang & \\
\hline 26 & 0,05 & $\begin{array}{l}\text { sangat } \\
\text { rendah }\end{array}$ & & & 0,19 & sukar & 0,30 & direvisi & dibuang & \\
\hline 27 & 0,04 & $\begin{array}{l}\text { sangat } \\
\text { rendah }\end{array}$ & & & 0,09 & sukar & 0,11 & direvisi & dibuang & \\
\hline 28 & 0,05 & $\begin{array}{l}\text { sangat } \\
\text { rendah }\end{array}$ & & & 0,13 & sukar & 0,11 & direvisi & dibuang & \\
\hline
\end{tabular}

Berdasarkan Tabel 4, dapat dilihat bahwa berdasarkan validitasnya, terdapat 5 soal dengan tingkat validitas sangat rendah, 14 soal dengan tingkat validasi rendah, 6 soal yang cukup, dan 2 soal dengan validitas yang tinggi. Berdasarkan tingkat kesukarannya, terdapat 2 soal dengan kategori mudah, 21 soal dengan kategori sedang, dan 5soal dengan kategori sukar. Reliabilitas soal sebesar 0,73 termasuk kategori tinggi.

Berdasarkan hasil tersebut, penelitian menggunakan 24 soal argumentasi ilmiah, dimana 4 soal dibuang karena tidak valid dan memiliki daya pembeda ditolak.

Analisis peningkatan kemampuan argumentasi ilmiah siswa. Data peningkatan dianalisis dengan uji statistik dengan menggunakan program IBM SPSS Statistic 23. Langkah-langkah analisis data dari hasil kemampuan argumentasi ilmiah siswa sebagai berikut :

a. Menghitung rata-rata Gain ternormalisasi, yang merupakan perbandingan antara rata-rata skor gain yang diperoleh siswa dengan skor gain maksimum yang dapat diperoleh (Hake, 1998), secara matematis dapat dituliskan sebagai berikut:

$$
\langle g\rangle=\frac{\left\langle S_{\text {post }}\right\rangle-\left\langle S_{\text {pre }}\right\rangle}{S_{\text {maks }}-\left\langle S_{\text {pre }}\right\rangle}
$$

b. Menginterpretasikan skor rata-rata gain dinormalisasi dengan menggunakan tabel 3.13 berikut.

Tabel 3. Interpretasi Skor Rata-rata Gain dinormalisasi

\begin{tabular}{cc} 
Nilai $\langle$ g $>$ & Peningkatan \\
\hline $0,00<<\mathrm{g}>\leq 0,30$ & Rendah \\
$0,30<<\mathrm{g}>\leq 0,70$ & Sedang \\
$0,70<<\mathrm{g}>\leq 1,00$ & Tinggi \\
\hline & (Hake, 1998)
\end{tabular}

c. Menghitung skor gain dinormalisasi untuk setiap siswa

(Hake, 1998)

Gain yang dinormalisasi merupakan perbandingan antara skor gain yang diperoleh siswa dengan skor gain maksimum yang dapat diperoleh (Hake, 2002), secara matematis dapat dituliskan sebagai berikut. 
Sekretariat: Jurusan Pendidikan IPA, Fakultas Matematika dan Ilmu Pengetahuan Alam, Universitas Negeri Padang - Jl. Prof. Dr. Hamka, Air Tawar Padang, Sumatera Barat

E-mail :prodiipa16@gmail.com, Halaman website : http://www.semesta.ppj.unp.ac.id/index.php/semesta.

Jurnal SEMESTA, Vol.01, No.01, 2017 pp. 34-46

$$
g=\frac{S_{\text {post }}-S_{\text {pre }}}{S_{\text {maks }}-S_{\text {pre }}}
$$

\section{d. Uji Hipotesis}

Untuk menentukan statistika yang cocok pada pengujian hipotesis, maka terlebih dahulu dilakukan uji normalitas dan uji homogenitas data $\mathrm{N}$-gain. Jika data terdistribusi normal dan homogen, maka digunakan uji t.

1) Uji Normalitas

Uji normalitas digunakan untuk mengetahui apakah data data $\mathrm{N}$-gain yang diperoleh mempunyai distribusi (sebaran) yang normal atau tidak. Distribusi normal adalah salah satu distribusi yang digambarkan dalam grafik berbentuk lonceng. Berbentuk dua bagian yang simetris, dimulai dari sebelah kiri, menaik mencapai titik puncak tertentu selanjutnya mulai menurun namun tidak menyentuh garis horizontal.

Uji normalitas data $\mathrm{N}$-gain hasil penguasaan konsep dan kemampuan argumentasi ilmiah siswa kelompok eksperimen dan kelompok kontrol menggunakan uji Kolmogorov-Smirnov (Wahyono, 2009). Normalnya distribusi data dapat diketahui dari nilai signifikan (2-tailed) output IBM SPSS Statistic 23, jika lebih besar dari $\alpha=0,05$ maka data terdistribusi normal. Jika data N-gain terdistribusi normal maka sebaran data $\mathrm{N}$-gain mendekati nilai rata-rata $\mathrm{N}$-gain, dimana sebagian data $\mathrm{N}$-gain lebih kecil atau sama dengan nilai rata-rata $\mathrm{N}$-gain, dan setengah lagi memiliki nilai lebih besar atau sama dengan nilai rata-ratanya.

Dengan kriteria sebagai berikut,

Jika nilai Sig $>0,05$, maka Ho diterima, $\mathrm{H}_{1}$ ditolak

Jika nilai Sig < 0,05, maka $\mathrm{H}_{1}$ diterima, Ho ditolak

Adapun hipotesis yang digunakan pada uji homogenitas adalah

Ho : data yang digunakan terdistribusi normal

$\mathrm{H}_{1} \quad$ : data yang digunakan tidak terdistribusi normal

2) Uji Homogenitas

Uji homogenitas digunakan untuk mengetahui apakah beberapa varian populasi adalah sama atau tidak. Uji homogenitas data N-gain hasil belajar ranah kognitif siswa kelompok eksperimen dan kelompok kontrol dilakukan dengan menggunakan uji Levene dalam One-Way Anova pada taraf signifikan $\alpha=0,05$. Uji ini didasarkan pada rumus statistik yaitu uji statistik F (Ruseffendi, 1998) yaitu:

$$
F=\frac{\text { Varians terbesar }}{\text { Varians terkecil }}
$$

Homogenitas data dapat diketahui dari nilai signifikan (2-tailed) output SPSS, jika lebih besar dari $\alpha=0,05$ maka data homogen atau varian sama (Wahyono, 2009). Sehingga bisa dikatakan bahwa kedua kelas memiliki karakteristik yang sama.

Dengan kriteria sebagai berikut,

Jika nilai Sig $>0,05$, maka Ho diterima, $\mathrm{H}_{1}$ ditolak

Jika nilai $\mathrm{Sig}<0,05$, maka $\mathrm{H}_{1}$ diterima, Ho ditolak

Adapun hipotesis yang digunakan pada uji homogenitas adalah

Ho : data yang digunakan berasal dari varians yang sama

$\mathrm{H}_{1} \quad$ : data yang digunakan berasal dari varians yang berbeda

Pengujian hipotesis dalam penelitian ini menggunakan uji-t satu ekor (one tail) dengan taraf signifikansi $\alpha=0,05$. Jika data berdistribusi normal dan homogen maka digunakan uji statistik dengan rumus :

$$
t=\frac{\bar{x}-\bar{y}}{\left(\frac{\left(n_{x}-1\right) S_{x}^{2}+\left(n_{y}-1\right) S_{y}^{2}}{n_{x}+n_{y}-2}\right)\left(\frac{1}{n_{x}}+\frac{1}{n_{y}}\right)}
$$

Keterangan :

( Uyanto,2009) 
Jurnal SEMESTA, Vol.01, No.01, 2017 pp. 34-46

$$
\begin{aligned}
& \overline{\mathrm{x}}=\text { rata-rata gain kelompok eksperimen } \\
& \overline{\mathrm{y}}=\text { rata-rata gain kelompok kontrol } \\
& \mathrm{n}_{\mathrm{x}}=\text { jumlah sampel kelompok eksperimen } \\
& \mathrm{n}_{\mathrm{y}}=\text { jumlah sampel kelompok kontrol } \\
& \mathrm{Sx}=\text { varians kelompok eksperimen } \\
& \mathrm{Sy}=\text { varians kelompok eksperimen }
\end{aligned}
$$

Kriteria pengujian dengan membandingkan taraf signifikansi hitungan $\mathrm{P}$ dengan $\alpha=0,05$, jika taraf signifikansi hitungan lebih kecil dari 0,05 , maka $\mathrm{H}_{1}$ diterima atau dengan membandingkan $\mathrm{t}_{\text {hitung }}>\mathrm{t}_{\text {tabel }}$. Maka $\mathrm{H}_{1}$ diterima pada taraf signifikansi $\alpha=0,05$.

\section{Hasil dan Pembahasan}

Kemampuan argumentasi ilmiah siswa diukur pada kedua kelas yakni kelas kontrol dan kelas eksperimen. Peneliti mempersiapkan tujuh wacana dengan soal berjumlah 28 , yang terdiri dari topik karakteristik zat, suhu, kalor, lapisan bumi, dan sifat cahaya. Dalam menyusun instrumen kemampuan argumentasi ilmiah, peneliti terlebih dahulu membuat kisi-kisi soal argumentasi ilmiah. Pada kisi-kisi argumentasi ilmiah terdapat komponen argumentasi ilmiah diantaranya klaim, data, pembenaran, dan dukungan. Klaim merupakan pernyataan yang diajukan agar diterima secara umum, seperti sebuah kesimpulan, sebuah jawaban atas sebuah pertanyaan atau masalah. Data adalah data ilmiah yang mendukung klaim dan data ilmiah adalah data yang berupa informasi seperti observasi dan pengukuran. Pembenaran yaitu alasan yang membenarkan hubungan antara data dan klaim. Sedangkan dukungan adalah asumsi dasar atau teori yang memberikan pembenaran untuk penjelasan tertentu.

Terdapat empat konsep yang diukur dalam membuat kisi-kisi instrumen argumentasi ilmiah, yakni konsep karakteristik zat, kalor dan perpindahannya, lapisan bumi dan optik. Kisi-kisi instrumen argumentasi ilmiah secara lengkap dapat dilihat pada. Selanjutnya kisi-kisi soal argumentasi ilmiah divalidasi oleh dua dosen ahli. Terdapat beberapa perbaikan ketika hasil validasi soal diberikan. Perbaikan diantaranya berupa soal yang dirasa kurang cocok dalam mengukur kemampuan argumentasi, kesalahan pengetikan dan jawaban yang tidak sesuai. Hasil validasi instrumen argumentasi ilmiah dapat dilihat pada. Selanjutnya peneliti memperbaiki instrumen argumentasi ilmiah yang telah divalidasi dan siap untuk diuji cobakan kepada siswa Sekolah Menengah Pertama.

Uji coba dilakukan kepada siswa kelas IX pada salah satu SMP di kota Padang. Hasil analisis uji coba soal argumentasi ilmiah dapat dilihat pada Tabel 3.9. Analisis lengkap soal uji coba argumentasi ilmiah dapat dilihat pada. Hasil analisis uji coba soal argumentasi didapatkan 4 soal yang tidak dapat dipakai, 4 soal yang terdapat pada satu wacana. Instrumen argumentasi ilmiah siswa siap untuk diberikan sebagai instrumen pengukur argumentasi ilmiah siswa.

Tes argumentasi ilmiah terdiri dari 24 butir soal yang terdiri dari 6 wacana. Tes dilaksanakan sebanyak dua kali, yakni pada saat sebelum melaksanakan pembelajaran menggunakan bahan ajar IPA terpadu dengan tema Halo (pretest) dan setelah melaksanakan pembelajaran menggunakan bahan ajar IPA terpadu dengan tema Halo (posttest).

Penelitian yang dilaksanakan bertujuan untuk melihat pengaruh bahan ajar IPA terpadu terhadap kemampuan argumentasi ilmiah siswa. Apakah terdapat peningkatan kemampuan argumentasi ilmiah siswa setelah dilaksanakanannya pembelajaran IPA terpadu dengan menggunakan bahan ajar IPA terpadu dengan tema Halo.

Kemampuan argumentasi ilmiah siswa diukur dengan menggunakan soal essay sebanyak 24 soal dengan 6 wacana. Data hasil penelitian yaitu peningkatan kemampuan argumentasi ilmiah siswa berupa rata-rata nilai pretest (pretest) dan tes akhir (posttest) dalam skala penilaian 0 hingga 100. Adapun rekapitulasi hasil pretest dan posttest kemampuan argumentasi ilmiah siswa pada kelas eksperimen dimana kelas eksperimen merupakan kelas yang menggunakan bahan ajar IPA Terpadu dengan tema Halo sebagai salah satu sumber belajar dan kelas kontrol dapat dilihat pada Tabel 4. 
Sekretariat: Jurusan Pendidikan IPA, Fakultas Matematika dan Ilmu Pengetahuan Alam, Universitas Negeri Padang - Jl. Prof. Dr. Hamka, Air Tawar Padang, Sumatera Barat

E-mail :prodiipa16@gmail.com, Halaman website : http://www.semesta.ppj.unp.ac.id/index.php/semesta.

Jurnal SEMESTA, Vol.01, No.01, 2017 pp. 34-46

Tabel 4. Rekapitulasi Skor Rata-rata Pretest dan Posttest Argumentasi Ilmiah Siswa Kelas Eksperimen dan Kontrol

\begin{tabular}{clrrrrc} 
Kelas & \multicolumn{1}{c}{ Tes } & Xideal & Xmax & Xmin & $\overline{\boldsymbol{X}}$ & $<\mathbf{g}>$ \\
\hline \multirow{3}{*}{ Kontrol } & Pretest & 100 & 66,67 & 58,30 & 63,71 & \multirow{2}{*}{0,64} \\
& Posttest & 100 & 98,61 & 90,27 & 87,10 & \\
& Kriteria Peningkatan & & & & Sedang \\
& & & & & & \\
\multirow{5}{*}{ Eksperimen } & Pretest & 100 & 68,05 & 59,72 & 62,71 & 0,84 \\
& Posttest & 100 & 98,61 & 88,89 & 94,00 & \\
& Kriteria Peningkatan & & & & Tinggi \\
& & & & & & \\
\hline
\end{tabular}

Pada Tabel 4, terlihat bahwa kemampuan berargumentasi ilmiah untuk kelas eksperimen dan kelas kontrol sama-sama mengalami peningkatan, akan tetapi besar peningkatannya berbeda. Agar lebih jelas, perbedaan peningkatan kemampuan berargumentasi ilmiah antara kedua kelas tersebut dapat dilihat pada diagram pembanding nilai rata-rata pretest dan posttest antara kelas eksperimen dan kelas kontrol.

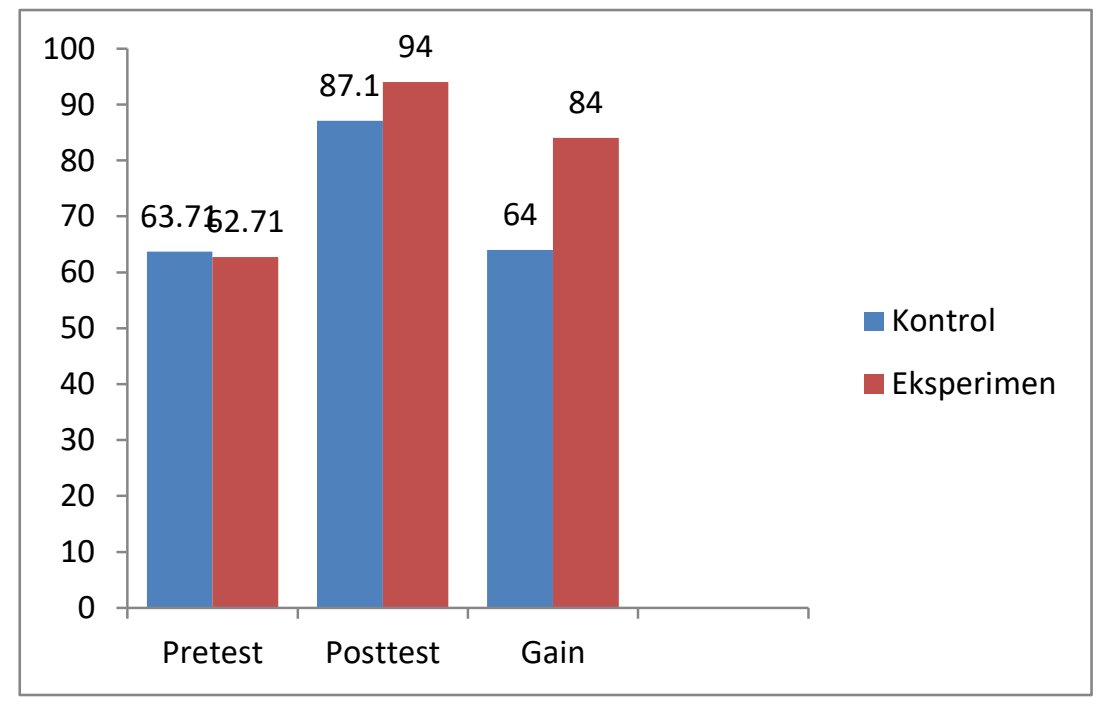

\section{Gambar 1. Diagram Pembanding Nilai Rata-rata Pretest, Posttest dan Gain antara Kelas Eksperimen dan Kelas Kontrol}

Pada Gambar 1 terlihat nilai pretest kelas kontrol memiliki selisih yang lebih tinggi dibandingkan dengan kelas eksperimen, yakni sebesar 0,83. Perbandingan nilai tes akhir penguasaan konsep kelas kontrol memiliki nilai yang lebih rendah jika dibandingkan dengan kelas eksperimen. Dimana pada posttest kedua kelas memiliki selisih sebesar 6,9.

Kemampuan argumentasi ilmiah siswa diuji dengan menggunakan soal essai dengan cakupan materi perubahan wujud zat dan kalor. Hasil yang diperoleh dapat dilihat pada Tabel 4.15. Dapat dilihat bahwa nilai rata-rata pretest kelas kontrol lebih tinggi jika dibandingkan dengan kelas eksperimen pada saat pretest. Pada kelas kontrol didapatkan rata-rata sebesar 63,71 sedangkan dikelas eksperimen diperoleh nilai rata-rata sebesar 62,71. Sehingga kelas kontrol dan kelas eksperimen memiliki selisih nilai sebesar 1,00. Sebelum dilakukan uji statistik, peneliti terlebih dahulu melakukan uji normalitas 
dan homogenitas untuk melihat apakah kelas eksperimen dan kelas kontrol memiliki distribusi yang normal dengan varians yang homogen. Hasil uji normalitas menunjukkan bahwa kedua kelas terdistribusi normal dan memiliki varians yang homogen. Maka, peneliti melakukan uji t dan didapatkan hasil bahwa tidak terdapat perbedaan yang signifikan pada kedua kelas.

Setelah diberikan bahan ajar IPA Terpadu dengan tema Halo, peneliti melakukan posttest dimana rekapitulasi hasil posttest dapat dilihat pada Tabel 4.19. Pada Tabel 4.19 dapat dilihat bahwa kedua kelas mengalami peningkatan dalam kemampuan berargumentasi. Hasil posttest memperlihatkan bahwa kelas eksperimen mendapatkan nilai rata-rata yang lebih tinggi dibandingkan kelas kontrol, dimana kedua kelas memiliki selisih nilai rata-rata sebesar 6,9. Peneliti melakukan uji normalitas dan uji homogenitas pada kedua kelas untuk melakukan uji hipotesis. Kedua kelas memiliki distribusi normal dan varians yang homogen, sehingga uji hipotesis yang dilakukan adalah uji t. Hasil uji t yang dilakukan adalah kedua kelas memiliki perbedaan yang signifikan.

Hasil pengujian hipotesis membuktikan bahwa bahan ajar IPA Terpadu dengan tema Halo mempengaruhi kemampuan argumentasi ilmiah siswa pada kelas eksperimen. Hal tersebut dibuktikan bahwa kelas eksperimen berhasil mendapatkan nilai rata-rata yang lebih tinggi jika dibandingkan dengan kelas kontrol dan kedua kelas berbeda secara signifikan. Pada dasarnya kedua kelas memiliki siswa yang aktif dalam pembelajaran, terutama dalam menjawab pertanyaan-pertanyaan spontan yang diajukan oleh guru, namun kelas eksperimen cendrung lebih kritis dan lebih percaya diri dalam mengutarakan pendapat jika dibandingkan dengan siswa-siswa dari kelas kontrol.

Selanjutnya untuk melihat apakah pengaruh tersebut berupa peningkatan kemampuan argumentasi ilmiah siswa, maka dilakukanlah uji t terhadap gain yang didapkan dari kedua kelas. Hasil rekapitulasi uji t terhadap gain yang didapatkan dari kedua kelas dapat dilihat pada Tabel 5.

Tabel 5. Rekapitulasi Hasil Uji t Gain Kemampuan Argumentasi Ilmiah Siswa

\begin{tabular}{cccccc} 
Gain & \multirow{N}{*}{ (Jumlah) } & \multicolumn{2}{c}{ Uji Homogenitas } & \multicolumn{2}{c}{ Uji t } \\
& & Sig. & Interpretasi & Sig. & Interpretasi \\
\hline Kontrol & 32 & \multirow{2}{*}{0,064} & $\begin{array}{c}\text { Varians data } \\
\text { homogen }\end{array}$ & 0,000 & $\begin{array}{c}\text { Terdapat perbedaan } \\
\text { Eksperimen }\end{array}$ \\
\hline
\end{tabular}

Siswa pada kelas eksperimen dilatih untuk memberikan argumen, baik lisan ataupun tertulis meskipun argumen yang disampaikan terkadang dirasa kurang tepat. Venville dan Dawson (2010) mengatakan bahwa siswa yang dilatih berargumentasi dan aktif dalam kelas argumentasi lebih mampu memproduksi argumen tertulis yang rasional. Disinilah peran guru sebagai fasilitator meluruskan pendapat siswa yang keliru tersebut. Ketika siswa belajar tentang sains sebaiknya guru tidak hanya menekankan pada penguasaan materi namun juga bagaimana cara berpendapat secara ilmiah dimana siswa didorong untuk memberikan gagasan berdasarkan data atau pengetahuannya. Sesuai dengan penelitian sebelumnya oleh Khun (1993; 2010 dalam dalam Garcia-Mila et al., 2013) yang mengatakan bahwa seharusnya pendidikan sains tidak hanya menekankan pada penguasaan konsep sains semata namun juga pada diskusi ilmiah yang tepat.

Ketika melaksanakan kegiatan diskusi, peserta didik dapat memperoleh pengalaman otentik, mengumpulkan data, dan bekerja sama. Pembelajaran seperti ini akan menciptakan iklim belajar yang menyenangkan. Aktifnya siswa berdiskusi dan melakukan kegiatan pratikum dapat memicu siswa untuk lebih tertarik dalam pembelajaran (Sari, 2013). Berland dan Hammer (2012) mengungkapkan bahwa langkah pertama untuk membantu perkembangan argumentasi siswa yaitu menciptakan lingkungan belajar dimana siswa paham tentang apa yang akan dikerjakan dan tujuan dari diskusi, dan meluruskannya dengan argumentasi ilmiah. Dalam diskusi yang dilakukan, siswa cenderung mengkonfirmasi kebenaran konsep yang mereka peroleh dari praktikum yang dilakukan. Walaupun diskusi dalam kelas sains sering dilakukan, tidak berarti bahwa peserta didik secara aktif terlibat dalam penalaran dan argumentasi ilmiah (Choi et al., 2013). 
Pada saat dilaksanakannya pembelajaran, siswa masih memiliki kebingungan dalam membuat argumen. Pada saat siswa mulai membuat argument secara tertulis, siswa cenderung kesulitan dalam menghubungkan klaim yang dipilih dengan data ataupun teori yang mendukung sehingga siswa harus selalu dibimbing. Kind et al. (2011) juga mengatakan bahwa siswa membutuhkan bantuan saat mereka menyampaikan, mengidentifikasi ataupun mengevaluasi klaim menggunakan teori ilmiah atau data. Dari hal ini dapat dilihat bahwa siswa harus selalu dibiasakan untuk belajar berargumen baik lisan maupun tertulis. Selain itu, siswa juga harus dilatih untuk memilih data ataupun teori yang akan digunakan sebagai pendukung argumennya.

Dalam membiasakan dalam berargumen membutuhkan waktu yang lama seperti penelitian Kind et al. (2011) yang membutuhkan waktu lebih dari dua minggu atau Osborne et al. (2004 dalam Kind et al., 2011) yang melaporkan sembilan bulan perlakuan terlalu singkat bagi siswa untuk mengembangkan keterampilan dan kemampuan tersebut.

Penelitian yang dilakukan oleh Osborne et al. (2004 dalam Venville dan Dawson, 2010) menemukan bahwa argumentasi peserta didik dengan usia 12-13 tahun meningkat setelah pemberian perlakuan selama satu tahun walaupun secara statistik hal ini tidak signifikan. Jadi semakin sering peserta didik dikondisikan untuk berargumentasi dengan metode mengajar pendidik yang mendukung akan dapat meningkatkan kemampuan peserta didik dalam berargumen.

Dalam berargumentasi, akan muncul saat ketika pendapat antara satu siswa dengan siswa lainnya tidaklah sama, maka permintaan pembenaran muncul, siswa akan berusaha memberikan alasan dari klaimnya tersebut. Perbedaan pendapat yang muncul diantara siswa akan memicu mereka membangun argumennya masing-masing. Choi et al. (2013) dari hasil penelitiannya juga menemukan bahwa siswa juga tetap ingin mengetahui kebenaran-kebenaran yang terkandung dalam sebuah argumen dan ingin mendapatkan fakta-fakta yang benar dan relevan dengan topik yang sedang dikaji. Argumentasi memberikan kesempatan bagi siswa untuk membangun pengetahuan dan pemahaman mereka menggunakan semua informasi yang relevan maupun tidak, menghubungkan antar konten, dan meningkatkan kemampuan peserta didik dalam menjelaskan pengetahuan ilmiahnya.

Selanjutnya disajikan jawaban-jawaban siswa pada lembar posttest argumentasi ilmiah. Gambar 2 dan Gambar 3 merupakan salah klaim yang diberikan oleh siswa pada lembar posttest. Gambar 3 merupakan siswa pada kelas ekperimen dan memperlihatkan klaim dengan skor sempurna, yakni 3. Gambar 3 memperlihatkan klain dengan skor sempurna yakni 3 pada kelas kontrol.

\section{perubahan fisika, karena ferjadi karen a sunu,}

\section{Gambar 2. Klaim Jawaban siswa pada Lembar Posttest Kelas Kontrol}

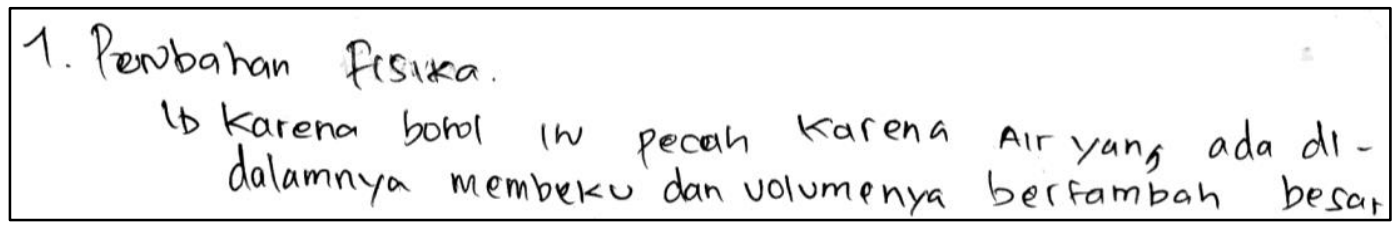

Gambar 3. Klaim Jawaban siswa pada Lembar Posttest Kelas Eksperimen

Menggunakan bahan ajar IPA terpadu sebagai salah satu sumber belajar, dapat melatih kemampuan argumentasi ilmiah siswa. Pada bahan ajar, masalah yang diberikan dibahas secara terpadu dan siswa dilatih untuk dapat berargumentasi secara ilmiah. Hal ini terbukti dengan nilai gain ternormalisasi pada kelas eksperimen mendapatkan interpretasi yang tinggi, pada keempat komponen argumentasi ilmiah, yakni klaim, data, pembenaran dan dukungan. Sedangkan pada kelas kontrol gain pada komponen pembenaran terinsterpretasi sedang. Siswa pada kelas kontrol cendrung sulit untuk menghubungkan antara klaim yang diberikan dengan data. Jawaban yang diberikan siswa dirasakan 
Sekretariat: Jurusan Pendidikan IPA, Fakultas Matematika dan Ilmu Pengetahuan Alam, Universitas Negeri Padang - Jl. Prof. Dr. Hamka, Air Tawar Padang, Sumatera Barat

E-mail :prodiipa16@gmail.com, Halaman website : $\underline{\text { http://www.semesta.ppj.unp.ac.id/index.php/semesta. }}$

Jurnal SEMESTA, Vol.01, No.01, 2017 pp. 34-46

masih kurang tepat meskipun dukungan berupa teori dapat dijelaskan dengan sangat baik oleh siswa pada kelas kontrol.

Berikut merupakan salah satu contoh jawaban siswa dalam menjawab pertanyaan essay argumentasi untuk soal no 9, 10, 11, dan 12

"Pakaian hitam akan lebih dahulu kering"

"Contohnya adalah aspal di jalanan, aspal akan terasa sangat panas pada siang hari dan sangat dingin pada malam hari, atau ketika memakai baju hitam disiang hari makan kita akan lebih kepanasa dari pada baju putih"

"Pakaian hitam dan aspal memiliki warna yang sama, yakni hitam, kedua benda tersebut akan menyerap kalor lebih baik dibandingkan dengan benda lain dengan warna yang lebih terang"

"Sesuai dengan teori radiasi bahwa semakin gelap warna suatu benda maka semakin banyak / semakin baik benda tersebut dalam menyerap kalor"

Sedangkan dalam berdiskusi saat pembelajaran terkadang siswa masih sering kesulitan dalam merangkai kata-kata untuk mengungkapkan klaim, data, pembenaran dan dukungan. Sehingga, siswa harus mencatat apa yang ingin disampaikannya terlebih dahulu. Terkadang siswa juga masih malumalu untuk mengutarakan argumentasinya.

\section{Kesimpulan}

Berdasarkan pembahasan dari data hasil penelitian, dapat disimpulakan. Peningkatan argumentasi ilmiah antara kelas kontrol dan kelas eksperimen berbeda secara signifikan. Dimana kelas eksperimen yang belajar dengan menggunakan bahan ajar IPA terpadu dengan tema Halo mendapatkan nilai $\mathrm{N}$-Gain pada kategori tinggi $(0,84)$ berbeda dengan kelas kontrol yakni kelas yang menggunakan bahan ajar IPA terpadu konvensional mendapatkan nilai N-Gain pada kategori sedang $(0,64)$.

\section{Ucapan Terima Kasih}

Alhamdulillahhirabbilalamin, puji dan syukur tiada hentinya diucapkan atas karunia, kesehatan, kelancaran, keberkahan, kesabaran dan kemampuan yang telah diberikan oleh Allah S.W.T kepada penulis sehingga dapat menyelesaikan penelitian ini. Tentunya sholawat dan salam diucapkan tiada hentinya kepada suri tauladan seluruh umat muslim, Nabi Muhammad S.A.W.

Proses penelitian tentunya tidak lepas dari bimbingan, dorongan, bantuan dan motivasi dari berbagai pihak. Oleh karena itu, pada kesempatan ini penulis ingin menyampaikan ucapan terima kasih dan pengahargaan setulusnya kepada :

a. Bapak H. Hayat Sholihin, M.Sc, PhD, dosen Pascasarjana Universitas Pendidikan Indonesia dengan penuh kesabaran memberikan bimbingan, dorongan, dan arahan kepada penulis selama penelitian berlangsung.

b. Bapak Dr. H. Riandi, M.Si, dosen Pascasarjana Universitas Pendidikan Indonesia dengan penuh kebijaksanaan memberikan bimbingan, motivasi, dan arahan kepada penulis selama penelitian ini berlangsung.

c. Seluruh Siswa kelas VII A dan VII F SMP N 1 Padang yang telah bersedia memberikan waktu dan kesempatan kepada peneliti untuk ikut serta dalam proses pembelajaran yang berlangsung.

d. Suami tercinta Mu'arif Arhas Putra, M.Pd yang selalu setia mendengarkan keluh kesah, membantu dan memberikan semangat penulis sedari awal hingga akhir penelitian dan penulisan.

e. Mama tercinta Syofiani Evita, S.Pd yang telah banyak bersabar, mencurahkan kasih sayang dan doa tiada hentinya kepada penulis dalam setiap hembusan nafas dan Papa tersayang (Alm) Annusyirwan Sm.Hk, meskipun tidak dapat bersama penulis, namun doa, usaha dan didikan papalah yang dapat membuat penulis tetap kuat dan berhasil menyelesaikan tesis ini.

f. Kakak-kakak tersayang Abu Hanifah, S.Kom, Widia Ayu Lestari S.T dan ipar-ipar Rini Fitriyeni, S.Kom, Ananda Teguh Prakoso, S.T atas segala doa dan tentunya keponakan-keponakan tercinta 
Sekretariat: Jurusan Pendidikan IPA, Fakultas Matematika dan Ilmu Pengetahuan Alam, Universitas Negeri Padang - Jl. Prof. Dr. Hamka, Air Tawar Padang, Sumatera Barat

E-mail :prodiipa16@gmail.com, Halaman website : $\underline{\text { http://www.semesta.ppj.unp.ac.id/index.php/semesta. }}$

Jurnal SEMESTA, Vol.01, No.01, 2017 pp. 34-46

Anindya Rizka Azalia, Azqya Putri Ayunda dan Alfahri Hafizd Azzikra yang selalu menjadi pengobat lelah dan rindu penulis.

Penulis menyadari sebagai manusia, penulis tidak luput dari kesalahan dan kekhilafan dalam penyusunan tesis ini. Oleh karena itu, penulis sangat berharap kritik dan saran yang sifatnya dapat membangun dan dapat membuat karya tulis ini menjadi lebih baik lagi. Semoga apa yang didapat selama penulisan tesis ini dapat bermanfaat bagi penulis sebagai suatu pelajaran hidup yang berharga maupun bagi pihak lain yang meneladaninya

\section{Daftar Pustaka}

Abidin, Y. (2014). Desain Sistem Pembelajaran Dalam Konteks Kurikulum 2013. Bandung: PT. Refika Aditama.

Acar, O \& Patton, B.R. (2012). Argumentation and formal reasoning skillsin an argumentationbased guided inquiry course. Social and Behavioral Science. Vol. 46. Hlm. 4756-4760.

Adian, D, G. \& Pratama, H, S. (2013). Teknik Berargumentasi, Berpikir sebagai Kecakapan Hidup. Jakarta : Kencana.

Andreson, R.D. (2002). Reforming Science Teaching: What Research says about Inquiry. Journal of Science Teacher Education. Vol.13. No.1. hlm. 1-12.

Arikunto, S. (2003). Manajemen Penelitian. Jakarta : Rineka Cipta.

Arikunto, S. (2006). Prosedur Penilaian Suatu Pendekatan Praktik. Jakarta : Rineka Cipta.

Arikunto, S. (2009). Dasar-dasar Evaluasi Pendidikan. Jakarta : Bumi Aksara.

Berland \& Hammer. (2012). Framing For Scientific Argumentation. Journal Of Research in Science Teaching, 49 (1), hlm. 68-94.

Berland, L.K \& Reiser, B. J. (2010). Classroom Communities'Adaptations of the Practice of Scientific Argumentation. Hlm. 191-196.

Bottcher, F \& Meisert, A. (2011). Argumentation in Science Education: A Model-based Framework. Journal of Science and Education. Vol. 20. Hlm. 103-140.

Bulgern, dkk. (2014). The Used and Effectiveness of an Argumentation and Evaluation Intervention inScience Classes. J Science Education Technology, 23, hlm. 82-97.

Choi, A., Hand, B. \& Norton-Meier, L. (2013). Grade 5 Student's Online Argumentation about Their In-Class Inquiry Investigations. Research Science Education

Christenson, N, et al. (2012). Using the SEE-SEP Model to Analyze Upper Secondary Student's Use of Supporting Reasons in Arguing Socioscientific Issues. Vol. 21 Issue 3, page 342. Swedia : Journal Science Education Technology.

Coladarci, T., Cobb, C.D., Minium, E. W., \& Clarke, R.B. (2011). Fundamental of Statistical Reasoning in Education, Third Edition. United States of America : Wiley.

Dahar, R.W. (2011). Teori-Teori Belajar dan Pembelajaran. Jakarta : Penerbit Erlangga.

Dawson, V., \& Venville, G.J. (2010). Teaching Strategies for Developing Students Argumentation Skills About Socioscientific Issues in High School Genetics. Research in Science Education, 40, hlm. 133-148.

Demircioglu, T \& Ucar, S. (2012). The Effect of Argument-driven Inquiry on pre-service science Teacher's Attitude and Argumentation Skill. Social and Behavioral Science. Vol. 46. Hlm. 50355039.

Departemen Pendidikan dan Kebudayaan. (2013). Lampiran Peraturan Menteri Pendidikan dan Kebudayaan Nomor 68 Tahun 2013 tentang Kerangka Dasar dan Struktur Kurikulum Sekolah Menengah Pertama.Madrasah Tsanawiyah. Jakarta: Depdikbud.

Depdiknas. (2006). Kumpulan Permen .Jakarta : Dirjen Dikti.

Depdiknas. (2008). Kumpulan Permen .Jakarta : Dirjen Dikti.

Depdiknas. (2010). Kumpulan Permen .Jakarta : Dirjen Dikti.

Eduran, S, Ozdem, Y \& Park, J.Y. (2015). Research trends on argumentation in science education: a journal content analysis from. International Journal of STEM Education. Vol.2. hlm. 5. 
Sekretariat: Jurusan Pendidikan IPA, Fakultas Matematika dan Ilmu Pengetahuan Alam, Universitas Negeri Padang - Jl. Prof. Dr. Hamka, Air Tawar Padang, Sumatera Barat

E-mail :prodiipa16@gmail.com, Halaman website : http://www.semesta.ppj.unp.ac.id/index.php/semesta.

Jurnal SEMESTA, Vol.01, No.01, 2017 pp. 34-46

Fogarty, R. (1991). How to Integrated the Curricula. Illinois: Skylight Publishing.

Frankel, J.R, Wallen, E.N., \& Hyun, H. (2012). How To Design and Evaluate Research in Education. Newyork : Mc. Graw Hill.

Garcia-Mila, M., Gilabert, S., Erduran, S. \& Felton, M. (2013). The Effect of Argumentative Task Goal on the Quality of Argumentative Discourse, Volume 97, No.4, pp. 497-523. Spanyol : Science Education

Gray, E. \& Nam-Hwa, K. (2014). The Structure of Scientific Arguments by Secondary Science Teachers: Comparison of experimental and historical science topics. International Jurnal of Science Education. Vol. 36. No. 1. Hlm 46-65.

Hake, R.R. (1999). Analyzing Change/ Gain Scores. United States of America : Indiana University.

Jin, H, dkk. (2015). A US-China Interview Study: Biology Students' Argumentation and Explanation about Energy Consumption Issues. International Journal of Environmental and Science Education. Vol. 10. No.3. hlm. 301-318.

Kim, H, \& Song, J. (2005). The Features of Peer Argumentation in Middle School Students' Scientific Inquiry. Research in Science Education.

Kind, P. M., Kind, V., Hofstein, A.\& Wilson, J. (2011). Peer Argumentation in the School Science Laboratory -Exploring Effects of Task Features. Vol 33 pp 2527-2558 ISSN 0950-0693 (print)/ ISSN 1464-5289 (online)/11/182527-32. United Kingdom : International Journal of Science Education.

Kulatunga, U., Moog, R. S. \& Lewis, J. E. (2013). Argumentation and Participation Patterns in General Chemistry Peer-Led Sessions. Vol. 50, No. 10,pp. 1207-1231 (2013). United Stated of America : Journal of Research in Science Teaching.

Lin, S.S., \& Mintzes, J. J. (2010). Learning Argumentation Skills Through Instruction In Socioscientific Issues : The Effect of Ability Level. International Journal of Science and Mathematics Education 8, hlm. 993 - 1017.

Macagno, A, dkk. (2012). What students' arguments can tell us. Using argumentation schemes in science education. International Journal of Science and Mathematic Education.

Nielse, J.A. (2011). Dialectical Features of Students' Argumentation: A Critical Review of Argumentation Studies in Science Education. Research in Science Education Journal.

Osborne, J., dkk. (2004). Enhancing the Quality of Argumentation in School Sciece. Journal of Research in Science Teaching, 41 (10), hlm. 994-1020.

Sadler, T,D. (2006). Promoting Discourse and Argumentation in Science Teacher Education. Journal of Science Teacher Education. Vol. 17. Hlm. 323-346.

Sampson, V. \& Clark, B D. (2009). A Comparison of the Collaborative Scientific Argumentation Practises of Two High and Two Low Performing Groups. vol. 41 issue 1 page 63 - 97. United States of America : Research Science Education.

Sampson, V., dkk. (2010). Argument-Driven Inquiry as a Way to Help Students Learn How to Participate in Scientific Argumentation and Craft Written Arguments : An Exploratory Study. Science Education, 95, hlm 217-257.

Sampson, V \& Blanchard, M.R. (2012). Science Teachers and Scientific Argumentation: Trends in Views and Practice. Journal of Research in Science Teaching.

Slavin, R.E. (1992). Research Method in Education 2nd Ed. USA : Allyn and Bacon.

Sudjana, N. (1990). Teknik Analisis Data Kualitatif. Bandung : Transito.

Sudjana, N. (2002). Metode Statistika. Bandung : Transito.

Sudjana, N. (1990). Penelitian Hasil Belajar Mengajar. Transito : Bandung.

Sugiyono. (2009). Metode Penelitian Kuantitatif Kualitatif dan $R \& D$. Bandung: Penerbit Alfabeta.

Swason, dkk. (2014). Engaging in Argument and Communicating Information:ACase Study of English Language Learners and Their ScienceTeacher in an Urban High School. Vol.51. No.1. hlm 3164. Australia: Journal of Research in Science Teaching.

Swirstra, T, \& Arie, R. (2007). Nano-ethics as NEST-ethics: Patterns of Moral Argumentation About New and Emerging Science and Technology. Vol. 1. Hlm. 3-20. 
Jurnal SEMESTA, Vol.01, No.01, 2017 pp. 34-46

Squire, K.D \& Jan, M. (2007). Mad City Mystery: Developing Scientific Argumentation Skills with a Place-based Augmented Reality Game on Handheld Computers. Journal of Science and Technology. Vol. 16. No.1. hlm. 5-34.

Venville, G. J. \& Dawson, V.M. (2010). The Impact of a Classroom Intervention on Grade 10 Students' Argumentation Skills, Informal Reasoning, and Conceptual Understanding of Science, Volume 47,No.8, PP.952-977. Australia: Journal of Research in Science Teaching.

Young \& Freedman. (2002). Fisika Universitas Edisi Kesepuluh Jilid II. Jakarta : Erlangga.

Yun, S.M \& Heui, B.K (2014). Changes in Students' Participation and Small Group Norms in Scientific Argumentation. Research in Science Education. Springer.

Zhou, G. (2010). Conceptual Change in Science : A Process of Argumentation. 6(2). hlm. 101-110. 